Published in: M. Lee (ed.), Strategies of Argument: Essays in Ancient Ethics, Epistemology, and Logic (Oxford: OUP) 2014, pp199-227.

\title{
Alexander of Aphrodisias on Aristotle's theory of the Stoic indemonstrables
}

\author{
Susanne Bobzien
}

In her important 1979 paper "Aristoteles über Syllogismen 'aufgrund einer Hypothese"," Gisela Striker provided an in-depth analysis of these vexing and perplexing Aristotelian arguments. She showed that they were Aristotle's way of providing a logical vehicle for inferences based on other than term-logical relations; that the 'hypothesis' that gives them their name is best understood as a rule that is not based on a relation of terms, ${ }^{2}$ rather than as a premise; and that in those arguments "the thing taken instead" ( ò $\mu \varepsilon \tau \alpha \lambda \alpha \mu \beta \alpha \nu$ ó $\mu \varepsilon v o v$ ) is an assertion that is used instead of the demonstrandum. ${ }^{3}$ It was upon reading this paper that I realized that the (then) prevalent interpretation of later ancient texts on hypothetical syllogisms as presenting the Stoic theory of indemonstrables needed a thorough revision. For it is possible to show that, starting from Aristotle's "syllogisms based on a hypothesis", a specifically Peripatetic, (and from the third century CE also partly Platonist) development can be traced through the centuries up to the late ancient passages on hypothetical syllogistic in Philoponus and Boethius. Although the Stoic indemonstrables undoubtedly played a role in this development, the various theories of hypothetical syllogisms over the centuries are all Peripatetic (and sometimes a little Platonist) in form, function and terminology. ${ }^{4}$ The present paper looks at Alexander of Aphrodisias' role in this development.

Alexander's commentaries on Aristotle's Organon are valuable sources for both Stoic and early Peripatetic logic, and have often been used as such - in particular for early Peripatetic hypothetical syllogistic and Stoic propositional logic. ${ }^{5}$ By contrast, /200/ this paper explores the role Alexander himself played in the development and transmission of those theories. There are three areas in particular where he seems to have made a difference: (1) First, he drew a connection between certain passages from Aristotle's Topics and Prior Analytics and the Stoic indemonstrable arguments, and, based on this connection, appropriated the Stoic indemonstrables as Aristotelian. (2) Second, he developed and made use of a specifically Peripatetic terminology in which to describe and discuss those arguments - which facilitated the integration of the indemonstrables into Peripatetic logic. (3) Third, he made some progress towards a solution to the

\footnotetext{
${ }^{1}$ Striker [1979]. See now also Striker [2009], 174-8, 201, 237- 238.

${ }^{2}$ Striker [1979], 46.

${ }^{3}$ Ibid., 43.

${ }^{4}$ Here I am in agreement with Maroth [1989]. The arguments the Stoics called hypothetical syllogisms were completely different from those the Peripatetics called hypothetical syllogisms: see my [1997].

5 E.g. Mueller [1969], Frede [1975], Goulet [1978], Barnes [1984], [1985], Mignucci [1993], Ierodiakonou, [1990], Bobzien [1996], Speca [2001].
} 
problem of what place and interpretation the Stoic third indemonstrables should be given in a Peripatetic (and Platonist) setting. ${ }^{6}$ Before I discuss these points in detail, here are some general remarks about Alexander and the context in which his contribution to the development of a Peripatetic theory of hypothetical syllogistic should be seen.

Alexander, like his older contemporary Galen and the Middle-Platonists, was faced with the Stoic five kinds of indemonstrables and with a rudimentary early Peripatetic theory of four types of hypothetical syllogisms, both seemingly covering the same logical ground. ${ }^{7}$ The Stoic theory and the terminology that came with it was generally known and taught, and parts of it at least had become standard logic and standard terminology, learned, used and/or referred to by members of all philosophical schools in the $1^{\text {st }}$ and $2^{\text {nd }}$ century CE. ${ }^{8}$ The early Peripatetic 'theory' was known to Galen, and the fact that some fragments of it are also preserved in Alexander, and in some later texts, suggests that later Peripatetics were familiar with it. Galen, despite displaying a preference for the Peripatetic-Platonist approach to logic, remains eclectic in his Institutio Logica and does not officially side with any school. ${ }^{9}$ By contrast, and not surprisingly, Alexander always defends the Aristotelian or Peripatetic line and habitually attacks the Stoics. Yet this had not been the manner of all Peripatetics: in the first century BC, Boethus appears to have adopted the Stoic indemonstrables wholesale, terminology and all (Galen, Inst.Log.7.2, see below Section 2.2). Propriety in matters of logic - as in other areas of philosophy - seems /201/ to have developed, together with a more historicophilologically orientated study of the texts of Plato and Aristotle, only after the turn of the millennium. The competition between the philosophical schools (and various other factors, no doubt) led to the desideratum that each of the founding philosophers have a view or dogma (if not a theory) on every philosophical subject matter - including those which had seen the light of day only after their death. These include prominently fate, the criterion of truth, and propositional logic; all three philosophical standard topics in the 2nd century CE, and all three introduced into philosophy only in Hellenistic times, and not originally part of Plato's or Aristotle's philosophy. Thus, Alexander, or some recent predecessors of his, patched together a 'theory of fate' for Aristotle from several of Aristotle's writings, and in [Plutarch] On Fate we find a similar patchwork for Plato. ${ }^{10}$ In Ptolemy, we find a Peripatetic 'theory of the criterion', 11 in Alcinous (Didasc. ch.4) a Platonist one, pieced together from excerpts from Plato's dialogues. Similarly, as this paper intends to show, Alexander, or some recent predecessors, ${ }^{12}$ purposely credited Aristotle with a theory that corresponds to Stoic propositional logic (i.e. with a hypothetical syllogistic).

\footnotetext{
${ }^{6}$ For Alexander's view on the so-called 'wholly hypothetical syllogisms' see Bobzien [2000].

${ }^{7}$ For the Stoic indemonstrables see e.g. Frede [1974], Bobzien [1996]. For the early Peripatetic theory see Barnes [1985], Bobzien [2002a], [2002b].

8 Cf. e.g. S.E.P.H.II.157-59; Gal.Inst.Log.6.6; Cic.Top.12.53-14.57, Fin.IV.19.54-5; Plutarch, De E apud Delphos 386E-387C; Philo De Plantatione 115; Alcinous, Didasc.ch.6; Apul.Int.191.6-11, 201.4-11, 209.9-14, 212.10-12; Aulus Gellius, N.A.XVI.8.1-8; Boethus Perip. acc. to Gal.Inst.Log.7.2; Lucianus Vitarum Auctio 24; [Galen] Hist.Phil.15.

${ }^{9}$ Bobzien [2004].

${ }^{10}$ Cf. Alexander On Fate 165.14-171.17 [Plutarch] On Fate 568b-574e.

${ }^{11}$ See Mark Schiefsky, this volume.

${ }^{12}$ In what follows, I suppress the adjunct 'or some recent predecessors'; but readers should keep in mind that it is virtually impossible to decide whether a certain innovation is Alexander's or whether he adopted it from lost Peripatetic commentators of the previous generation.
} 
Unlike in the case of fate, we have no extant separate treatise by Alexander on hypothetical syllogistic. ${ }^{13}$ We have to rely on some remarks and brief discussions in his commentaries on Aristotle's Prior Analytics and Topics. Alexander likely also considered some material relevant to hypothetical syllogistic in his lost commentaries on the Categories and De Interpretatione. ${ }^{14}$ So there is no evidence that Alexander ever attributes a worked-out theory of hypothetical syllogisms to Aristotle. Rather, what is remarkable is that Alexander persistently (if not always consistently) interprets and presents passages from Aristotle's Organon in a light that makes it appear as if Aristotle was in the possession of a Peripatetic correlate to the Stoic theory of indemonstrables.

/202/

\section{The connection of passages from Aristotle's Organon with the Stoic theory of indemonstrables and the appropriation of the latter as Aristotelian}

Alexander draws two connections between Aristotle's logic and the Stoic indemonstrables: first, a connection with Aristotle's 'syllogisms from a hypothesis', and second, a connection with two of Aristotle's topoi.

\subsection{Aristotle's syllogisms from a hypothesis and the Stoic indemonstrables}

There are four passages germane to the first connection, all in Alexander's Analytics commentary. ${ }^{15}$ In each of the four passages, Alexander either states or implies that the indemonstrables are a subclass of Aristotle's 'syllogisms from a hypothesis'. In one, in addition, he actually undertakes to show this. First, his mere claims and suggestions that there is a connection: (italics mine)

(1) To those 'by means of another hypothesis', as he (i.e. Aristotle, An.Pr.41a40f) ${ }^{16}$ said, presumably also belong the arguments which are the only ones that the more recent <philosophers> want to call syllogisms. These are the arguments that come to be by means of the mode-forming 〈premise>, as they say, and the co-assumption, the mode-forming premise being either a conditional or a disjunction or a conjunction. (Alex.An.Pr.262.28-31) ${ }^{17}$

(2) ... or, after he (i.e. Aristotle) has said which of the hypotheticals clearly fall under the presented method (these are both the <arguments> through the impossible, and the <arguments> in accordance with that-which-is-taken-instead (metalepsis) - which include all of the so-called indemonstrables - and the arguments in accordance with a quality) ... (Alex.An.Pr.326.3-5)

\footnotetext{
${ }^{13}$ The view until recently held by the majority of scholars that Ibn Sina (Avicenna) provides evidence for the existence of a treatise by Alexander on hypothetical syllogisms has been laid to rest by Street [2001].

14 Thus, in Ammonius' and Al Farabi's De Interpretatione commentaries we find classifications of hypothetical propositions or premises, and Al Farabi's short Categories commentary contains a

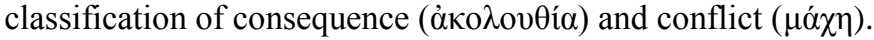

15 Alex.An.Pr.262.28-265.5, 326.4-5, 386.27-30, 389.31-390.1, 3-6. Potentially relevant: An.Pr.325.37326.1 and 386.22-3.

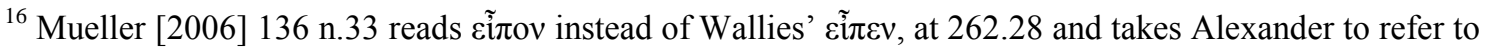
the earlier passages Alex.An.Pr.262.9 and 262.28-264.31.

${ }^{17}$ For reasons of word limit, and with some regret, I refer the reader to the TLG (Thesaurus Linguae Graecae) for the Greek text from Alexander.
} 
(3) (i) Having talked about the <arguments> from agreement and the ones that lead to the impossible, Aristotle says that there are many other arguments that also conclude from a hypothesis; he defers speaking about these with more care. ... . /203/ (ii) He would mean the hypothetical <arguments> by means of thatwhich-connects, which is also called a conditional, and the co-assumption, and the ones by means of that-which-divides, that is disjunction, and perhaps the ones by means of the negation of a conjunction. (Alex.An.Pr.389.31-390.1, 390.3-6)

(4) The <arguments> which prove something by leading to the impossible, too, are "from a hypothesis" ... . <This is> so also in the case of the hypothetical $<$ arguments> by means of that-which-connects, and similarly <in the case of the hypothetical arguments> by means of that-which-divides. That which has been posited is not accepted by means of syllogisms but because of the hypothesis; the syllogism is of something else. ${ }^{18}$ (Alex.An.Pr.386.22-23, 27-30)

It appears that the clauses in italics were all used by Alexander to denote the same types of argument. He refers to them in different ways, but his glosses in passage (3) make it clear that he intends the same argument types each time. The Stoic terminology in (1), (2), and (3) ('mode-forming', 'co-assumption', 'conditional', 'disjunction', 'negation of a conjunction', 'indemonstrable') and the reference to the more recent philosophers suggest that these are the arguments the Stoics call indemonstrables. (The terminology is discussed in detail in Section 2.) On this assumption that Alexander intends the same types of argument each time, taken together the passages suggest he envisages a classificatory scheme of Aristotle's syllogisms from a hypothesis as sketched in Figure $1 .^{19} / 204 /$

Figure 1

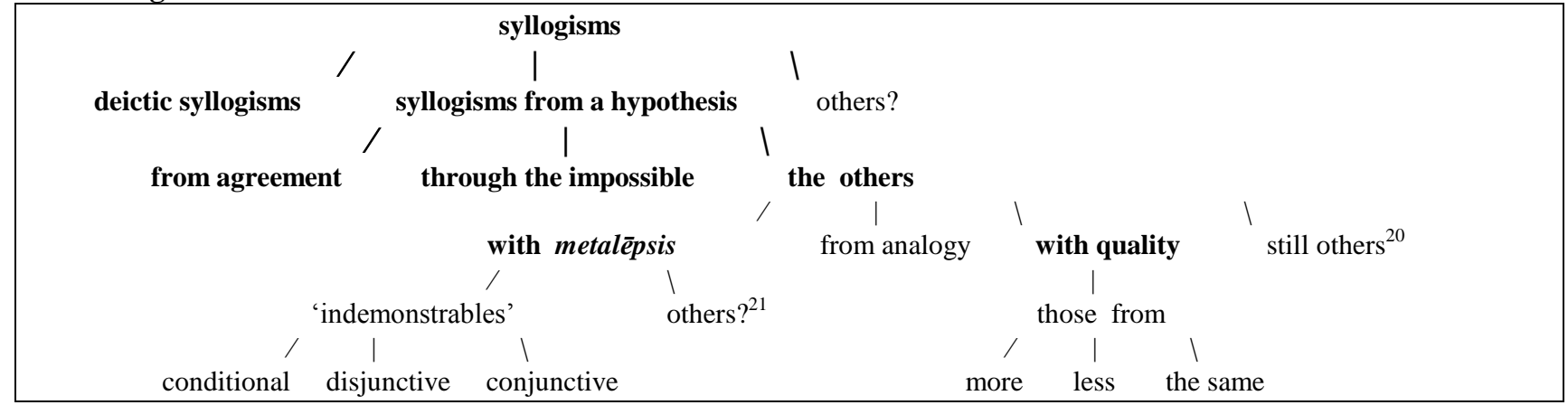

If Alexander did not envisage a scheme similar to this, he worked with several incompatible schemes. (Aristotle's text is far from clear on the logical relation between the different types of syllogism he mentions.)

\footnotetext{
${ }^{18}$ For the details of these arguments see Striker [1979].

${ }^{19}$ Types with correlates in Aristotle in bold. For syllogisms from a hypothesis see Arist.An.Pr.A.23,29,44; "through the impossible": 41a22-37, 45a23-b15, 50a29-38; "from agreement: 50a16-28, 33-5; "with metalepsis" and "with quality": 45b15-19; "others": 41a37-41, 45b15-16, 50a39-b2.

20 'Those with some other kinds of hypothetical premises which have been discussed elsewhere': we don't know where Alexander discussed these.

${ }^{21}$ From passage (2) it's unclear whether Alexander thought the so-called indemonstrables exhausted the syllogisms with metalepsis.
} 
Taken literally, Alexander's classification of the Stoic indemonstrables seems clearly anachronistic. At the time the Stoics introduced them, Aristotle had been dead for some time. Should we say that in classifying the Stoic indemonstrables as Aristotelian, Alexander confuses Peripatetic hypothetical syllogisms with Stoic indemonstrables ${ }^{22}$ I believe this puts things the wrong way. Rather, Alexander assumed that humans generally make use of certain ways of arguing or patterns of inference (e.g. we argue from 'if Diotima is breathing, then Diotima is alive' and 'Now Diotima is breathing' to 'Diotima is alive'), and they are justified in doing so, since the resulting arguments are valid; and that both Aristotle and the Stoics theorized about such arguments: the Stoics in a way that is at least partially wrong, and Aristotle in the right way. Just that, unfortunately, Aristotle did not leave in writing a full theory of such arguments. And, as elsewhere, where Aristotle has not left a worked-out theory or terminology, Alexander supplies one in - what he takes to be - the Aristotelian spirit. Several factors suggest that this was Alexander's approach. Like Galen, he polemicised against what he regarded as the Stoic 'formalism', i.e. their way of determining what kind of argument or proposition something is by its linguistic form, rather than by its meaning; ${ }^{23}$ in his view, the Stoics systematized the inference /205/ patterns at issue in the wrong way and, in the wake of this, allowed useless arguments to count as syllogisms. However, Alexander never doubts that there are underlying syllogisms which the Stoics get wrong, and which Aristotle and the Peripatetics get right. Similarly, he thinks the Stoics thought - wrongly - that the 'indemonstrables' were indemonstrable, whereas Aristotle did not make this mistake. Again, Alexander believes that the Stoics - wrongly thought that the indemonstrables were syllogisms because they are evidently valid basic (non-demonstrable) arguments, whereas he (in agreement with Aristotle, or so he assumes) holds that they are syllogisms because they demonstrate that something does or does not hold (of something). That is why he usually calls them 'so-called indemonstrables' (cf. e.g. passages (2), (6), (7), (10)).

Thus we are made to believe that the arguments the Stoics call 'indemonstrables' belong to a class of syllogisms which Aristotle was aware of, but did not himself fully develop. Alexander fits them into an Aristotelian classification of syllogisms. As part of this classification, they then automatically sport a number of properties, i.e. all those which the more generic types of syllogisms of the classificatory scheme share: being Aristotelian syllogisms, they demonstrate that something holds or does not hold (of something) $;{ }^{24}$ they have more than one premise and no redundant premises. (Stretching his master's stance to the limit, Alexander also assumes that the so-called indemonstrables come about through the three figures of the categorical syllogisms and are brought to completion through the first figure (cf.Arist.An.Pr.A23.)) As hypothetical syllogisms, the search concerns that-which-is-taken-instead ( cf.Arist.An.Pr.A29 and below Section 2.2), and "they cannot be led back from the things hypothesized" (cf.Arist.An.Pr.A44).

\footnotetext{
${ }^{22}$ As suggested by Speca [2001] 52-3, 56.

${ }^{23}$ E.g. Alex.An.Pr.373.18-20, 28-35.

${ }^{24}$ Unclear whether they are meant to fit Aristotle's definition of the syllogism.
} 
By integrating the 'indemonstrables' into a presumed Aristotelian taxonomy and describing them in Peripatetic terms, ${ }^{25}$ Alexander makes it look plausible that they are of Aristotelian origin and thus appropriates them.

In the long passage An.Pr.262-5, Alexander goes beyond merely stating that the arguments the Stoics call 'indemonstrables' are Aristotelian syllogisms from a hypothesis; he also undertakes to show they are. He proceeds as follows: he provides examples of several indemonstrables, and, by describing them in the way Aristotle describes his example of a syllogism from a hypothesis demonstrates that they fit Aristotle's description of the "other" syllogisms from a hypothesis (Arist.An.Pr.A44). In particular, he $/ 206 /$ focuses on the points (i) that the second premise must be proved ${ }^{26}$ by a categorical syllogism; (ii) that the conclusion (the thing-to-be-proved) is established by means of ( $\left.\delta \dot{t}^{\prime}\right)$ the hypothesis, i.e. the first premises; (iii) that this hypothesis in turn needs no proof, and in fact cannot be proved. ${ }^{27}$

Alexander's argument is unimpressive. First, he presupposes that the second premise of the indemonstrables is a 'categorical statement', with distinct subject and predicate terms. Thus he excludes existential statements such as 'providence exists'. Aristotle's syllogisms from a hypothesis may have excluded such cases, ${ }^{28}$ but the Stoic indemonstrables certainly did not. Second, Alexander presupposes that the modeforming ( $\tau \rho о \pi \iota \kappa \alpha ́)$ premises (which he re-interprets as hypotheses) are posited as 'wellknown' $(\gamma v \omega ́ \rho \mu \alpha)$. Again, most Stoics would not have agreed, though Aristotle would. ${ }^{29}$ So we have the choice of either charging Alexander with a petitio principii; or saying that at most he has shown that the indemonstrables, if understood in a Peripatetic way, tally with Aristotle's theory of syllogisms from a hypothesis. Either way, the Stoics would have no reason to think that their indemonstrables have anything to do with Aristotle's logic. Presumably this does not matter for Alexander. He gives the Peripatetics some reasons for believing that the (inference patterns that lie behind the) Stoic indemonstrables are the sort of thing Aristotle had in mind as some of the "other syllogisms from a hypothesis". From a Peripatetic perspective, they do fit, give and take, the general conception of the "other syllogisms from a hypothesis" that can be extracted from the Aristotelian passages.

\subsection{Aristotle's Topics and the Stoic indemonstrables}

Alexander draws a second connection between Aristotle's logic and the Stoic indemonstrables on pages 165-6 and 174-5 of his Topics commentary. Here he connects the Stoic indemonstrables with some topoi from Aristotle's Topics. The first passage on which Alexander comments is from Topics II.4:

(5) One must examine, regarding the point at issue, [i] what is such that if it is, the point at issue is, or [ii] what is by necessity, if the point at issue is: [i] if one

\footnotetext{
${ }^{25}$ For Alexander's use of terminology see also Section 2.

26 'To prove' is here used not as strictly as in Arist.An.Post.

${ }^{27}$ Cf. Alex.An.Pr.264.32-265.13. Still, if it had to be proved, this, too, would have to happen by means of a categorical syllogism (Alex.An.Pr.263.22-5).

${ }^{28}$ See my [2002a].

${ }^{29}$ The - probably - Stoic accounts of 'argument' in S.E.PH.2.136 and M.7.301-2 suggest that some Stoics thought the premises in an argument must be agreed upon by the discussants.
} 
wants to establish something, one must examine what there is such that if it is, the point at issue will be (for when the former has been proved to hold, the point at issue will also have been proved to hold); [ii] if, on the other hand, one wants to refute $/ 207 /$ something, one must examine what it is that is if the point at issue is (for when we prove that what follows from the point at issue is not, we will have destroyed the point at issue.) (Arist.Top.111b17-23)

Alexander describes this topos as 'twofold, since it can both establish and refute from a consequence'. ${ }^{30}$ He considers each sub-type of the topos separately, starting with a paraphrase of point [i] from Aristotle's text. Then he continues:

(6) for if the antecedent, then also the consequent, in accordance with the first socalled indemonstrable, which establishes from a consequence ... (Alex.Top.165.12-13)

and adds an example. Moving to the second sub-type, he again starts with a paraphrase of point [ii] from Aristotle's text. Then he continues

(7) for if the consequence <does> not <hold>, nor <does> the antecedent, in accordance with the second so-called indemonstrable, which refutes from a consequence ... (Alex.Top.166.11-13)

Again he adds an example. It is unclear, how exactly Alexander envisages the relation between the 'twofold' Aristotelian topos and the first two indemonstrables. He certainly believed that the two so-called indemonstrables are somehow related to the two ways of the topos: The topos is said to be 'establishing and removing from consequence', and the first so-called indemonstrable is said to be 'establishing from consequence'; the second to be 'removing from consequence'. Moreover, he seems to think that the socalled indemonstrables explain the corresponding sub-topos ('for if ...'). However, the exact purpose of the explanation is hard to gauge. Alexander talks about the so-called ${ }^{31}$ first and second indemonstrables. He seems to regard the so-called indemonstrables as patterns of inference or argument forms or schemata. His formulations ('for if ..., then also ...'; 'for if ..., neither ...') suggest that, these patterns can be used as justifications of the two sub-topoi. Thus Alexander considers these patterns called 'so-called indemonstrables' as logically prior to the topos. This, again, suggests that Alexander thinks of certain inference-patterns similar to modus ponens and tollens as existing valid patterns; patterns Aristotle was aware of and which /208/ the Stoics wrongly thought of as being indemonstrable. This is confirmed by another passage from Alexander's Prior Analytics commentary (Alex.An.Pr.336.13-20), in which Alexander couches two arguments in a Peripateticized version of the Stoic mode-arguments ${ }^{32}$, and then adds:

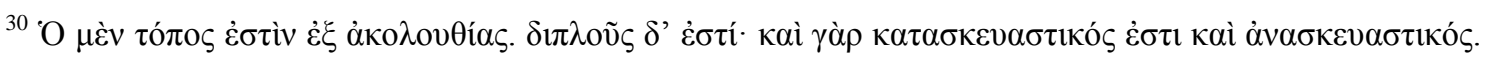
Alex.Top.165.6-7.

${ }^{31}$ The Stoics called indemonstrables the individual actual arguments that satisfied the descriptions of first, second, etc. indemonstrable. See my [1996] Section 1.

${ }^{32} \lambda$ оүо́
} 
(8) The establishing is in accordance with the second indemonstrable and the refuting is in accordance with the first. ${ }^{33}$

Here again the Aristotelian methods of establishing and refuting are said to be in

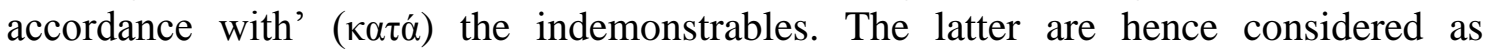
logically prior.

The second passage on which Alexander comments is from Aristotle's Topics II.6:

(9) In the case of things of which hold one and only one of two <predicates>, as for instance of a human being holds either illness or health, if we are well-equipped to argue about the one, that it holds or does not hold, we will also be wellequipped with regard to the remaining one; this converts with regard to both; for [iii] when we have proved that the one <predicate> holds, we will also have proved that the other does not hold; and [iv] when we prove that the one does not hold, we will have proved that the remaining one holds. (Arist.Top.112a2431)

In this case, the connection Alexander draws between the Aristotle passage and the indemonstrables is more complex. He starts with describing the topos as 'establishing or refuting from a conflict' ( Alex.Top.174.7). The parallel to his treatment of the previous topos is obvious. Taking his comments on the two passages (Alex.AnPr.165-6 and 174-5) together, we can see what Alexander did: He combined the Stoic pair of logical expressions 'consequence' and 'conflict' with the Peripatetic pair of 'establishing' and 'refuting'. It seems that this combination of the pairs of terms is not known before Alexander. We find it in some later texts, with slight variations that reflect further developments. ${ }^{34}$ So here Alexander may have been innovative. At any rate, in this passage we have evidence of one important step towards the incorporation of Stoic logic into Peripatetic and Platonist syllogistic. /209/

After this description of the topos Alexander interprets Aristotle's passage in the light of an Aristotelian logical distinction that originates with the Categories. The distinction is that of contraries without intermediates, contraries with intermediates, and contradictory opposites (which are not contraries and have no intermediates). In Categories 10, Aristotle classifies these as three different kinds of opposites ( $\dot{\alpha} v \tau \imath \kappa \varepsilon i ́ \mu \varepsilon v \alpha)$, and explains each one. ${ }^{35}$ Here Alexander draws another important connection: the Aristotelian kinds

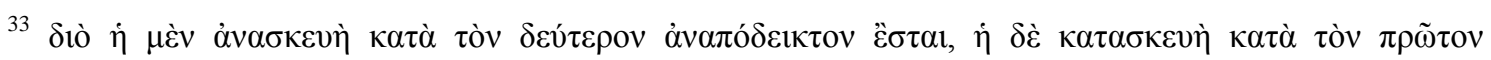
(Alex.An.Pr.336.18-20).

${ }^{34}$ Galen used this pair of terms for a Peripatetic logical distinction; but he didn't make the connection with the Topics; or if he did (in his lost commentaries?) this didn't survive.

${ }^{35}$ Arist. Cat.11b17-23, 11b38-12.a25, 13a37-b35 (cf. Amm.Cat.95.8ff). Aristotle's talks of contradictory opposites as 'things opposed as affirmation and negation'; Alexander uses the expression from the $D e$

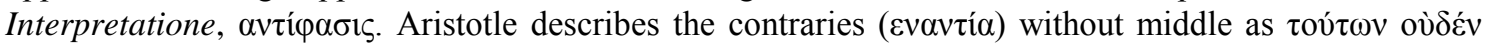

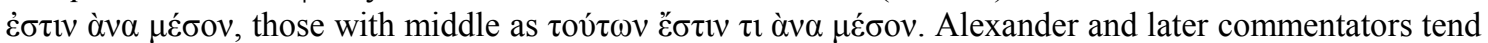
to use the terms $\varepsilon^{\prime} \mu \mu \varepsilon \sigma \alpha$ and $\alpha \mu \varepsilon \sigma \alpha$. Aristotle does not say that contradictory opposites have no middle, but such a description is in keeping with Cat.13a37-b35.
} 
of opposites are understood as three different types of conflict. Thus a Peripatetic logical distinction and a Stoic logical term are linked. ${ }^{36}$

Alexander suggests that in the cases of contraries without intermediates and of contradictories, the topos under discussion can be used both for establishing and for refuting. The connection between Aristotle's topos and the contraries without intermediates is obvious, and Alexander appears merely to spell out what Aristotle would have taken for granted. (Like Aristotle, Alexander only talks about contraries without combination, i.e. contrary pairs of terms, not contraries with combination, i.e. contrary pairs of sentences.)

The case of contradictories is also - if somewhat forced - dealt with within term logic: it holds of everything, if you have proved that something is affirmed of it, then you have refuted that that thing is negated of it, and vice versa. The topos under discussion can thus be used both for establishing and for refuting in the case of contradictories, too (Alex.Top.175.2-10). I am unsure whether this interpretation of the topos would have found Aristotle's approval.

Alexander's introduction of the opposites with intermediates into the topos would most probably not have found Aristotle's approval. Aristotle starts from a certain relation of terms (contraries without intermediates) and explains what inferential moves of establishing and refuting one can make given this relation. Alexander, by contrast, seems to have focussed on two general inference patterns that involve conflict. The text suggests that these two patterns are along the lines of "If $A$ and $B$ conflict, then if we have A, we have refuted B" and "If A and B conflict, then if we don't have A, we have established B". Starting from these patterns, Alexander investigates the $/ 210 /$ abovementioned three Aristotelian types of opposites, as to whether they "fit" them. He concludes that contradictories and contraries without intermediates fit both patterns, but contraries with intermediates fit only the pattern for refuting. Once more, Alexander appears to regard the patterns of inference as independent of and prior to the specific topos under discussion, and as having wider application than the topos. The passage in Aristotle's Topics betrays no such assumption of underlying independent inference patterns. Again, Alexander's specific interpretation of an Aristotelian passage facilitates his drawing a connection with the Stoic indemonstrables: the fourth and fifth indemonstrable show markedly clearer similarities to Alexander's two inference patterns than to Aristotle's Topics passage.

Alexander introduces the indemonstrables at the very end of his comments on the Topics passage:

(10) And the proof that is fitting for the <contraries> without intermediates is rather the one by means of the so-called fifth indemonstrable, which is the one that concludes from that-which-divides and the contradictory to one of the <components> in that-which-divides the remaining <component>. But for the contraries with intermediates the <proof> by means of the fourth <so-called indemonstrable is fitting>, which is the one that refutes from that-which-divides

\footnotetext{
${ }^{36}$ He illustrates the cases of contraries with examples from Arist.Cat.10 and adds further examples from other Aristotelian works.
} 
and one of the <components> in that-which-divides the other <component>. (Alex.Top.175.21-6)

In this passage, Alexander does not mention the Aristotelian contradictories at all. His correlation of the two types of contraries with the fourth and fifth types of indemonstrables seems unique. We discuss his correlation of the fourth indemonstrables with the contraries with intermediates in Section 3.2. Here we note that what he says about contraries without intermediates is unexpected, given his earlier remarks on the contraries. We would have expected him to say that both the fourth and the fifth indemonstrable fit the case of contraries without intermediates. Yet he correlates only the fifth with these. ${ }^{37}$

We disregard this problem and focus on Alexander's positive input. He reports the Stoic description of the fifth indemonstrables almost correctly, with the exception of some terminological modification (for which see below and Section 2.2)./211/ But the use he makes of this description is distinctly un-Stoic. The Stoic theory of indemonstrables is a theory of basic formally valid arguments to which all more complex formally valid arguments can be reduced, but which themselves need no proof. ${ }^{38}$ The Stoics would simply say that everything with the form described is a fifth indemonstrable. This includes arguments from false premises and arguments that in the disjunction have the same component assertible twice. Alexander despises this focus on the mere validity of arguments, since it produces useless argument forms. ${ }^{39}$

What interests Alexander is how one can produce proofs by using valid inference patterns. Proofs need to have true premises. Alexander (in line with Aristotle's Topics) considers first what types of complex premises are such that their instances are always true. In the case at issue, the relevant types must all fit the general pattern of dividing premises/propositions. They turn out to be those types of dividing hypothetical premises in which the two components express opposites: the dividing premises/propositions are always true if they express contraries with intermediates; or contraries without intermediates; or contradictories. Second Alexander considers by addition of what true categorical premises/propositions one can then establish or refute something.

The Stoic fourth and fifth indemonstrables are thus re-interpreted as general inference patterns and put to a distinctly Peripatetic use within Peripatetic logic: they provide the general pattern for proofs that refute or establish something from a conflict ( $\mu \alpha \dot{\chi} \chi)$ of things. Three of Aristotle's types of opposites are interpreted as three different types of conflict; each can be used for producing proofs. Thus, again, the indemonstrables are treated as logically prior to the topos at issue.

The details of this use of the Stoic indemonstrables are messy. Alexander's commentary on the topos (Alex.Top.174-6) before the introduction of the indemonstrables is done in terms of term-logic. Where Alexander introduces the descriptions of the

\footnotetext{
${ }^{37}$ We note that to his credit, Alexander makes his statement sound tentative, using the expression 'rather' $(\mu \tilde{\alpha} \lambda \lambda \mathrm{ov})$. Of course, the idea that both patterns fit, but one may fit somewhat better than the other is also not terribly attractive.

${ }^{38}$ Cf. my [1996] Section 1.

${ }^{39}$ Cf. e.g. Alex.An.Pr. 18.12-22.
} 
indemonstrables, he leaves out all nouns that would allow us to pin them down as Stoic or as Peripatetic:

... the so-called fifth indemonstrable, which is the one that concludes from thatwhich-divides and the contradictory to one of the <components> in that-whichdivides the remaining one. /212/

The Stoic version would be:

... the fifth indemonstrable, which is the one that concludes from a disjunctive assertible and the contradictory to one of its disjuncts the remaining disjunct. ${ }^{40}$

The Stoic relation of the disjunctive assertible and the assertibles that are used as disjuncts is such that the truth-value of the disjunctive assertible depends on the truthvalues (and modal relations) of the assertibles used as disjuncts. At the other extreme, we would have a Peripatetic version that does not acknowledge the existence of molecular propositions:

... the so-called fifth indemonstrable, which is the one that concludes from a dividing hypothetical premise and the contradictory to one of the terms in the dividing hypothetical premise the remaining term as holding of the object in question.

Various intermediate versions can be constructed. Since in our passage Alexander is commenting on the Topics, it is more likely here (than in his commentary on the Prior Analytics) that he considers 'naked' relations between terms rather then the relation between sentences or premises that contain two terms and share one term. But this is merely conjectural.

What matters are the following points: With the chosen formulations, Alexander does not commit himself to the elements of propositional logic in Stoic logic. Nothing suggests that that-which-divides is such that its truth-conditions depend on the truth (and modal relations) of some truth-bearers that function as its components. There is in fact no evidence that that-which-divides is thought to have logically independent components that are truth-bearers. Historically, the passage Alex.Top.174-6 is important, since it is the earliest that connects the fourth and fifth Stoic indemonstrables with Aristotle's Topics (and the only one in Alexander). Moreover, it is the earliest that connects the Stoic indemonstrables with Aristotle's theory of opposites. Later commentators take up both points and improve on them.

To sum up this section: Alexander has given the first two and the last two types of Stoic indemonstrables a home in Aristotelian dialectic. He has appropriated them as Peripatetic tools, in the form of argument patterns, for establishing or refuting theses. He has identified particular Aristotelian topoi which correspond to them, or which $/ 213 /$ are 'cases' or 'examples' of them. Moreover, he has connected two of the indemonstrables with Aristotle's theory of opposites from the Categories. Thus, in a second and third

${ }^{40}$ E.g. DL.7.81, SE.PH.2.158, Gal.Inst.Log.6.6. 
way, the indemonstrables (four of them, more precisely) have been anchored in Aristotle's logic.

\section{The development and use of a specifically Peripatetic terminology for the Stoic 'indemonstrables, ${ }^{41}$}

The greater awareness of the differences in the views of the various philosophical schools together with the philologically and historically more thorough study of the original texts of Aristotle and Plato in the second century CE (in contrast with the 1 st $\mathrm{BCE}$ ) is reflected in Alexander's choice and use of terminology. Thus, not only does he, in his comments on hypothetical syllogistic, bring together material from Aristotle, early Peripatetics, Stoics, and later Peripatetics (including himself); he also preserves and juxtaposes elements of at least four different (though partly overlapping) sets of terms:

(a) Although Aristotle had no terminology for hypothetical syllogisms (as he had no theory of such syllogisms), his general theory of logic, the terminology he used for syllogisms from a hypothesis, and the terminology used in the topoi discussed in Section 1.2 taken together provided Alexander with a basic stock of useful expressions.

(b) The early Peripatetics had made some rudimentary advancement towards a theory of hypothetical syllogisms and appear to have introduced some basic vocabulary that went beyond Aristotle's. ${ }^{42}$

(c) The Stoics had a complete set of technical terms for their syllogistic. ${ }^{43}$ When Stoic syllogistic became the logic of hypothetical syllogistic in the $1^{\text {st }}$ century $\mathrm{BCE}$, many Stoic terms became part of the common terminology used in logic, although we witness some modifications. ${ }^{44}$ Some Peripatetics of the $1^{\text {st }}$ BCE seem to have adopted together with parts of Stoic theory also parts of Stoic terminology. ${ }^{45}$

(d) In the second century CE, there is demand for a distinctly Peripatetic (and also for a distinctly Platonist) theory of hypothetical syllogistic. One way of marking /214/ out a distinct theory is by introducing a distinct terminology. This seems to be precisely what Alexander did. His surviving commentaries provide evidence that he deliberately replaced terms from the Stoic theory of indemonstrables by terms that are either taken from the closest Aristotelian or early Peripatetic correlates, or are coined with an eye to expressions from Aristotelian and early Peripatetic logic. For this purpose Alexander uses primarily two devices. First, he glosses one term

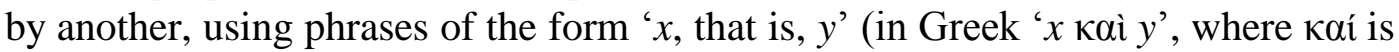
used epexegetically). He generally puts first the less familiar term (that is the Aristotelian, early Peripatetic, or newly coined one), and explains it with the one more familiar at his time, usually either the Stoic one, or the common term that had been developed from the Stoic one. Second, Alexander explicitly distances himself from the Stoic, or Stoic-derived common, terminology; he does this in particular where he thinks that the descriptive component of the term is inaccurate.

\footnotetext{
${ }^{41}$ This section requires knowledge of ancient Greek. It can be skipped.

${ }^{42}$ Cf. my [2002a], [2002b], [2004] for details.

${ }^{43}$ Cf. my [1996].

${ }^{44}$ Cf. Section 2.1 for some examples.

${ }^{45}$ Galen is a witness to this development, see my [2004].
} 
Alexander's use of the sets of terms (a) to (d) is not systematic. Nor is it random. Naturally, he employs Aristotle's own terms when he presents or paraphrases Aristotle's views. Where necessary, he explains them in terms of common or later Peripatetic terminology. ${ }^{46}$ Equally naturally, he uses Stoic terminology mainly when presenting and criticising Stoic theory. ${ }^{47}$ He sometimes makes use of Stoic terms that have become common coinage where there is no Peripatetic substitute or where he explains the early Peripatetic equivalents or newly introduced Peripatetic terms. However, he also sometimes uses more recent Peripatetic terms without glossing them in this way. This last fact suggests that these more recent Peripatetic terms were at the time already established to some degree among the Peripatetics, or at least among his students.

If Alexander's strategy as described in (d), was successful, we should have the Stoic theory of indemonstrables not only Peripatetically modified and firmly grounded in Aristotle's logical system, but also cleverly terminologically disguised in a way that would suggest to someone historically not on the ball that there has always been a worked-out Aristotelian theory that covered the same logical ground as the Stoic indemonstrables. I now consider Alexander's choice of terminology for hypothetical syllogistic in detail.

\subsection{Propositions or sentences and their components}

Alexander uses the Peripatetic term $\pi \rho$ ó $\alpha \sigma \sigma \varsigma$, , rather than the Stoic term $\dot{\alpha} \xi i \omega \mu \alpha$ ('assertible'), for propositions (or meaningful sentences). Like Aristotle and the /215/ early Peripatetics, he also uses $\pi \rho$ ó $\alpha \alpha \sigma \varsigma$ for 'premise'. To denote simple propositions,

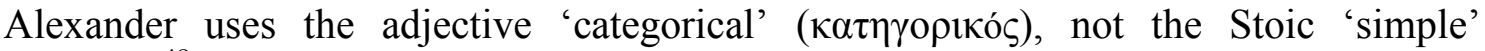
$(\dot{\alpha} \pi \lambda \circ \tilde{\nu} \varsigma){ }^{48}$ Thus Alexander uses an Aristotelian term, but in a different meaning than Aristotle himself; and he is aware of this. ${ }^{49}$ (This option must have seemed preferable to using a Stoic term.) Instead of the Stoic expression 'mode-forming propositions' ( $\tau \rho \circ \pi$ «ós, i.e. those which can be used as a complex premise in a Stoic syllogism)

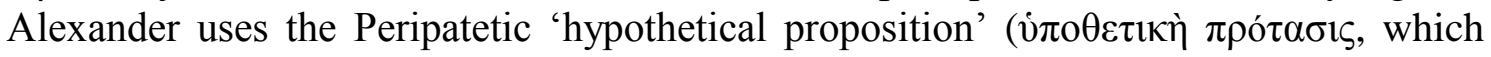
for the early Peripatetics seems to have meant 'hypothetical premise' and not 'hypothetical proposition'). ${ }^{50}$ There seems to be only one passage where Alexander

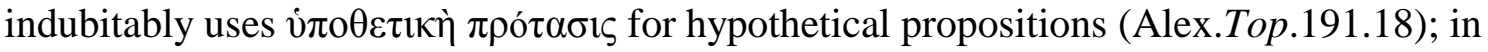
other passages it is unclear whether the intended meaning is proposition or premise (e.g. Alex.An.Pr.11.17-20, 17.7-8, 324.7, 327.2-3), and when Alexander reports Aristotle, it is likely intended as premise.

For the various kinds of mode-forming propositions, Alexander appears to introduce his own terms. In later antiquity, the Stoic terms for conditional and disjunctive assertibles

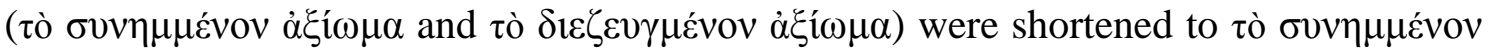
and $\tau$ ò $\delta 1 \varepsilon \zeta \varepsilon v \gamma \mu \varepsilon ́ v o v$ and took on a life outside Stoic logic, as independent noun phrases, not as elliptic for conditional assertible and disjunctive assertible. They were used by Peripatetic, Platonist, and other non-Stoic philosophers who would call propositions

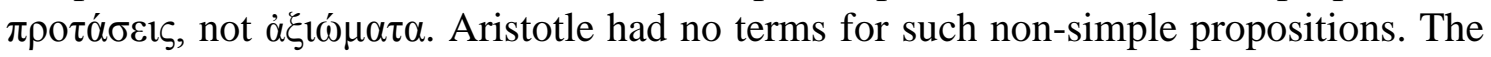

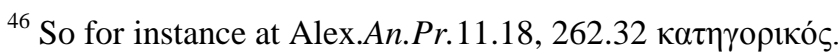

${ }^{47}$ So for instance $\dot{\alpha} \xi \dot{i} \omega \mu \alpha$, Alex.An.Pr.177.31, 179.32, 180.2; $\tau$ cò $\lambda \tilde{\eta} \gamma o v$ at Alex.An.Pr.177.21, 178.28.

${ }^{48}$ We find this also e.g. in Gal.Inst.Log.2.2, 6.2. Alcin.Didasc.11.15.

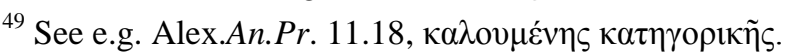

${ }^{50}$ See my [2002a] and [2002b].
} 
early Peripatetics - if we trust Galen ${ }^{51}$ - had words for the two types of relations

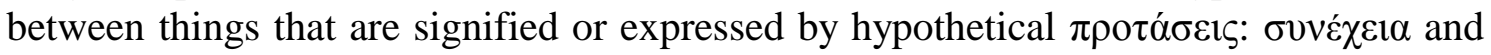

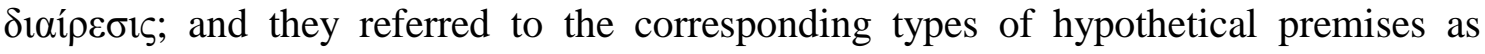

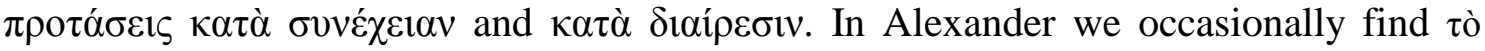
$\sigma v v \eta \mu \mu \varepsilon ́ v o v$ in non-Stoic contexts (Alex.Met.318.23). Much more frequently, we find

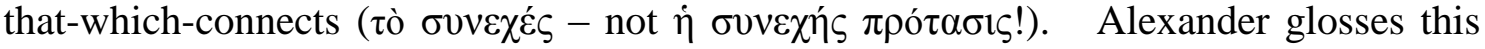

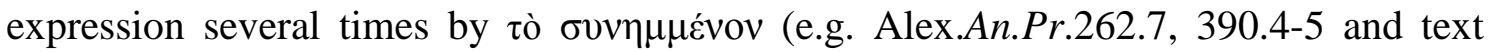

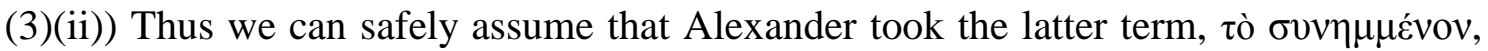
to be generally understood, and the former, tò $\sigma u v \varepsilon \chi \varepsilon \dot{\varepsilon} \zeta$, as in need of explanation. In

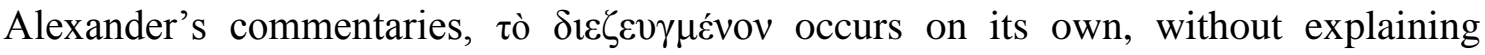
another term, only in Stoic context. In non-Stoic contexts Alexander uses it for glossing that-which-divides (

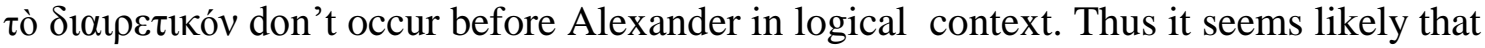
Alexander himself coined the two expressions in parallel to the /216/ original Stoic ones

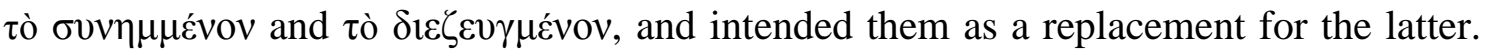
They could be understood as being truly Peripatetic, since they are formed in analogy

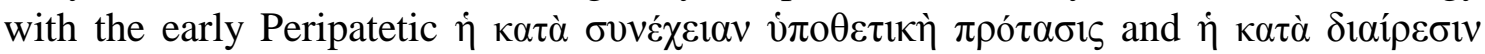

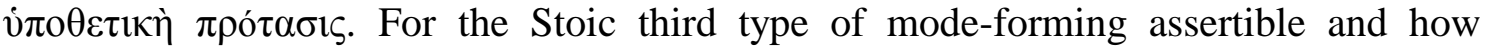
Alexander dealt with it, see Section 3 below. Here we only mention the following. The Stoics, in line with their propositional-logical approach, called these kinds of propositions conjunction-negating assertible ( $\dot{\alpha} \pi \circ \varphi \alpha \tau 1 \kappa o ̀ v ~ \sigma v \mu \pi \varepsilon \pi \lambda \varepsilon \gamma \mu \varepsilon \dot{v}$ ov $\dot{\alpha} \xi \hat{\xi} \omega \mu \alpha)$ or

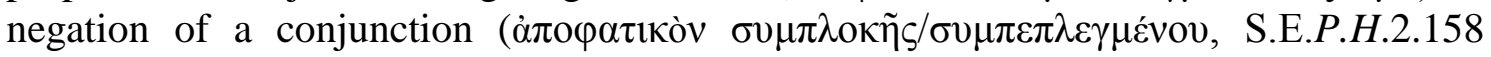
M.8.226, D.L.7.80): negation has the largest scope and thus the category of assertibles to which these belong is (non-simple) negations. We have a compound proposition, compounded from a negation and a conjunction by prefixing the negation particle to the conjunction. By contrast, Alexander (like Galen and most later ancient authors) called their equivalents a negative conjunction ( $\dot{\alpha} \pi \circ \varphi \alpha \tau \iota \kappa \tilde{\eta} ~ \sigma 0 \mu \pi \lambda о \kappa \tilde{\eta}$, below passage (11)). This, once more, suggests that the propositional-logical element from Stoic logic is lost. The negative conjunction is just another type of hypothetical premise/proposition from which inferences can be drawn.

The Stoic terms for the components in a conditional, i.e. the antecedent and the consequent, were $\tau$ ò $\dot{\eta} \gamma o u ́ \mu \varepsilon v o v$ and $\tau$ ò $\lambda \tilde{\eta} \gamma o v$. Alexander instead uses the Aristotelian

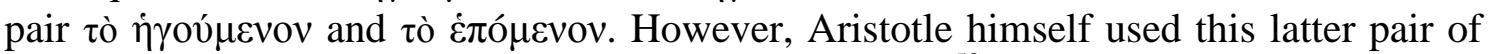
expressions mostly for terms rather than propositions. ${ }^{52}$ Thus we have another case where Alexander chooses an Aristotelian term but doesn't keep to Aristotle's main use of it.

\subsection{Syllogisms and their components}

The picture is similar for syllogistic. We saw that Alexander associated the Stoic indemonstrables with Aristotle's syllogisms from a hypothesis. This fact is reflected in his terminological choices. Where Alexander uses the name 'indemonstrable', he usually does so only with the addition 'so-called' ( $\lambda \varepsilon \gamma$ ó $\mu \varepsilon v o v)$. His reason for this is not just that the name is Stoic, but more importantly, that he thinks it to be inaccurate. The Stoics, and at least one Peripatetic, Boethus, believed the indemonstrables to be indeed

\footnotetext{
${ }^{51}$ See my [2002b].

${ }^{52}$ E.g. Arist.An.Pr. 43 b17.
} 
indemonstrable, i.e. not in need of proof since self-evident. ${ }^{53}$ The Peripatetics regarded some categorical syllogisms as indemonstrable, usually those of the first $/ 217 /$ figure. Alexander - purporting to follow Aristotle - accepts nothing but the first figure categorical syllogisms as indemonstrable. ${ }^{54}$ Hence for the types of arguments the Stoics call indemonstrables a different name is not just desired but philosophically required.

As the generic term Alexander uses 'hypothetical syllogism'. This may have been used already by earlier Peripatetics, or was in any case easily coined by taking Aristotle's phrase 'syllogisms from a hypothesis' as model. Alexander does not doubt that the arguments the Stoics call 'indemonstrables' (and the later so-called 'mixed' hypothetical syllogisms in general) are syllogisms. His justification of this fact is Aristotelian, however, not Stoic. 55

Alexander calls the first premises of the hypothetical syllogisms, generically, 'hypothetical premises'. ${ }^{56}$ It is less clear whether he had a way of referring to the specific kinds of premises. For the second premise, which the Stoics called co-

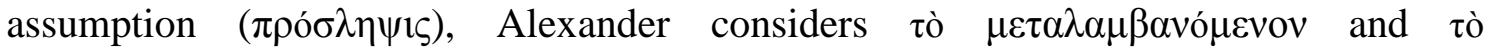
$\pi \rho \sigma \sigma \lambda \alpha \mu \beta \alpha v o ́ \mu \varepsilon v o v$. He takes these to be synonyms, the first being the term Aristotle and some early Peripatetics used, the second having been used by some early Peripatetics (perhaps in addition to the first) (An.Pr.19.4-5, 262.6-9. However, whereas in Aristotle $\mu \varepsilon \tau \alpha \lambda \alpha \mu \beta \alpha v$ ó $\varepsilon_{\varepsilon v o v}$ is used to indicate that the premise is that-which-istaken-instead, ${ }^{57}$ (instead of the conclusion, as that which is to be proved by a categorical syllogism, that is), ${ }^{58}$ Alexander interprets it as meaning 'changed assumption', in the sense that in the hypothetical proposition/premise, the component proposition $p$, say, is taken as being hypothesized only, whereas in the 'changed assumption', $p$ is taken to state that something is the case; it has thus changed - changed in its status of force, as we might say. ${ }^{59}$ This may show awareness at Alexander's time of what is called the 'Frege point' in contemporary philosophy.

Moreover, unlike the Stoics, Alexander at least sometimes takes $\pi \rho$ ó $\lambda \eta \psi 1 \varsigma$ (and also $\mu \varepsilon \tau \alpha \dot{\lambda} \eta \psi 1 \varsigma)$ to be the act of taking a proposition as the additional premise, and $\tau$ ò $\pi \rho \circ \sigma \lambda \alpha \mu \beta \alpha v o ́ \mu \varepsilon v o v$ and $\tau$ ò $\mu \varepsilon \tau \alpha \lambda \alpha \mu \beta \alpha v o ́ \mu \varepsilon v o v$ as the result of this act. For the Stoics the $\pi \rho \dot{\sigma} \lambda \eta \psi 1 \varsigma$ is an assertible (an incorporeal entity), ${ }^{60}$ taken as premise, never the act of taking the assertible as premise. (Similarly, Aristotle and Alexander sometimes use 'syllogism' for the act of deducing ('deduction'), whereas for the Stoics it always

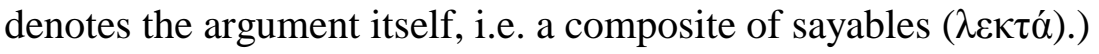

${ }^{53}$ Gal.Inst.Log.7.2. Maroth maintains that Galen reports a discussion within the Peripatetic school, in which Boethus defended the priority of the hypothetical before the categorical syllogisms (Maroth [1989] 246-7). However, in Galen the terminology and preceding context are Chrysippus' logic, and (pace Maroth) we have no evidence of the use of the pair of terms "categorical syllogism" and "hypothetical syllogism" before the $2^{\text {nd }}$ century CE.

${ }^{54}$ E.g. Alex.An.Pr. 24.2-12.

${ }^{55}$ Cf. e.g. Alex.AnPr 265.1-24.

${ }^{56}$ Cf. Alex. An.Pr.17.8-9, 326.6-7, Top.63.25, 191.18.

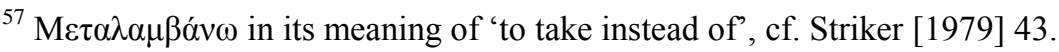

${ }^{58}$ See my [2002a].

${ }^{59}$ Alex.An.Pr.263.26-33; $\mu \varepsilon \tau \alpha \lambda \alpha \mu \beta \alpha ́ v \omega$ used in its meaning of 'to change'.

${ }^{60}$ E.g. D.L.7.76. 
For the five individual types of 'indemonstrable' syllogisms, there appears to have been no set of Peripatetic expressions on offer which Alexander could have adopted wholesale. To denote them, Alexander uses two different sets of description, each /218/ corresponding to one way he connected them with Aristotle's Organon (see Section 1). The first, found in Alexander's Analytics commentary, is based on his terms for conditionals and disjunctions (cf. Alex.An.Pr.390.3-5, 386.27-8, passages (3) and (4) above):

- the hypothetical syllogisms/arguments by means of that-which-connects, which is

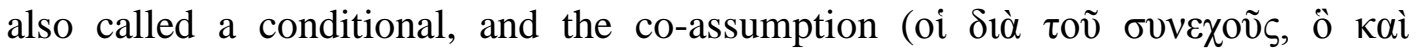

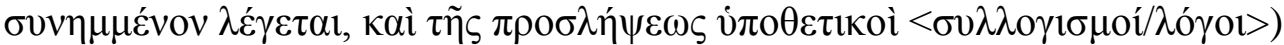

- the hypothetical syllogisms/arguments by means of that-which-divides, which is

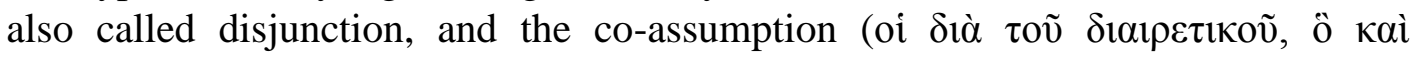

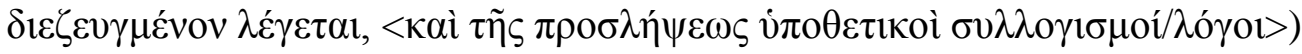

These are descriptions in the style of the early Peripatetics, ${ }^{61}$ each describing the two premises through which the syllogism comes about. In a second passage we find abbreviations of these descriptions: "the hypotheticals by means of that-which-

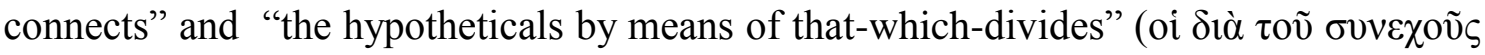

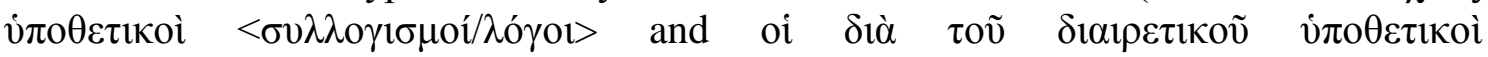
$\left.<\sigma v \lambda \lambda \gamma_{\gamma} 1 \sigma \mu \mathrm{o}^{\prime} / \lambda \mathrm{\gamma}_{\gamma o l}>\right)$. Whether these may actually have functioned as names, rather than mere descriptions, of these types of syllogisms is unclear. I have not found them in any author other than Alexander. In any event, these descriptions (or names) are clearly in the Peripatetic tradition, based on Aristotelian and early Peripatetic terms and descriptions of what was to become to be the hypothetical syllogisms. ${ }^{62}$

Alexander's second set of descriptions, the one in his Topics commentary, is based on his terminology for the relevant topoi. Alexander describes the relevant first topos as

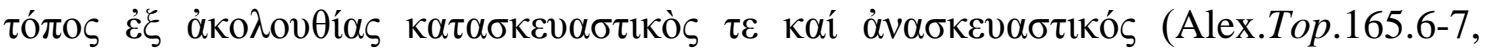
174.5-6); the first resulting syllogism as the first so-called indemonstrable, which is $\dot{\varepsilon} \xi$

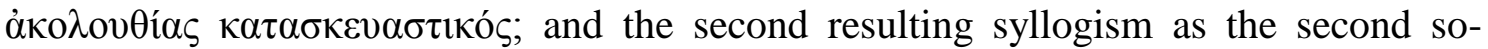

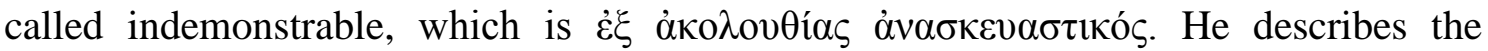

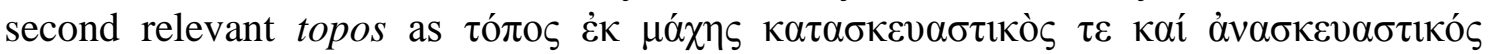
(Alex.Top.174.6-7); the first corresponding syllogism as the fifth so-called

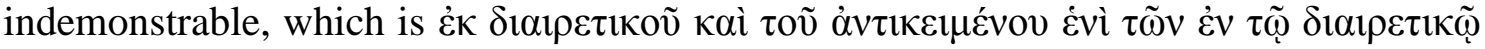

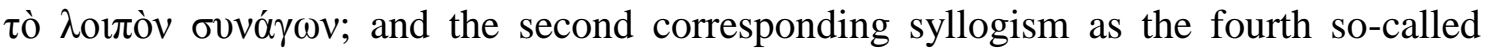

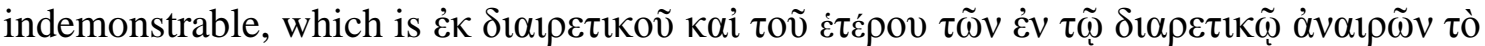

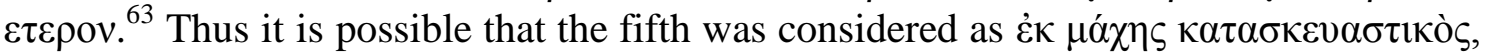

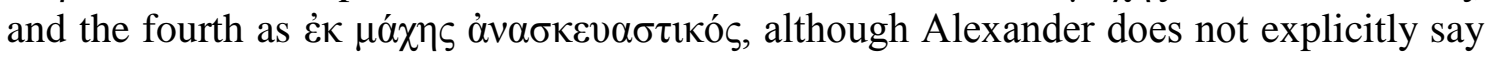
so. In any case, Alexander's description, even though it follows the Stoic standard

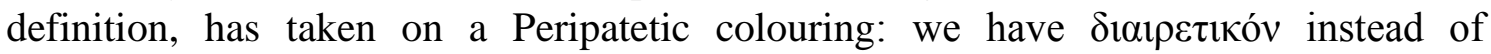

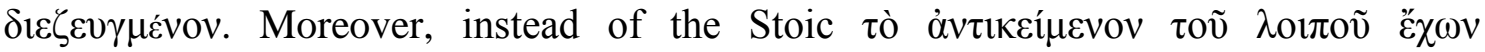

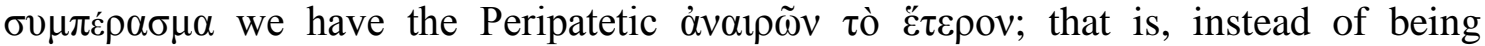
formulated in terms of contradictoriness, the conclusion is formulated in terms of

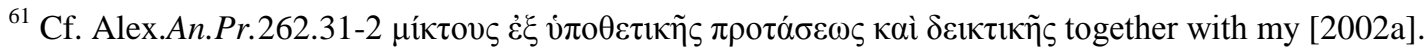

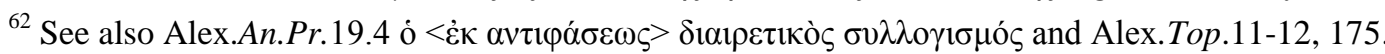

${ }^{63}$ Elsewhere he classifies a different kind of argument as fifth indemonstrable, see Section 3.
} 
refuting. Alexander is our earliest source for these features, and they all recur, further refined, in later Aristotle commentators. The fourfold descriptions of the 'indemonstrables' in terms of the two pairs of expressions 'consequence' and 'conflict' and 'establishing' and 'refuting' seem to be echoed in one text only, namely Alcinous' Handbook of Platonism (Didasc. ch.6). Alcinous' dates are uncertain, but he is likely to have been either a contemporary of Alexander or a generation or so later.

I conclude the present section with a table of the various expressions relevant to hypothetical syllogistic found in Alexander (or which he is likely to have known), sorted according to ascription and/or likely origin (Figure 2). /219/

Figure 2

\begin{tabular}{|c|c|c|c|}
\hline Aristotle & early Peripatetics $^{64}$ & Stoics & Alexander \\
\hline proposition / statement & proposition & simple assertible & categorical proposition \\
\hline - & $?$ & mode-forming proposition & hypothetical proposition \\
\hline- & $?$ & conditional assertible & that-which-connects \\
\hline- & $?$ & disjunctive assertible & that-which-divides \\
\hline - & $?$ & conjunctive assertible & conjunction? \\
\hline- & $?$ & negation of conj. assertible & negative conjunction? \\
\hline antecedent & antecedent & antecedent & antecedent \\
\hline consequent & consequent & 'ending' & consequent \\
\hline 'following' & connection & to follow & consequence \\
\hline ?'conflict' & division & to conflict & conflict \\
\hline (syllogism from hypoth.) & syll. from hypothesis & indemonstrable syllogism & $\begin{array}{l}\text { hypothetical syllogism / } \\
\text { so-called indemonstrable syllogism }\end{array}$ \\
\hline- & in acc. w. connection & first indemonstrable & $\begin{array}{l}\text { hyp.syll. through that-which-connects / } \\
\text { establishing from consequence }\end{array}$ \\
\hline- & in acc. w. connection & second indemonstrable & $\begin{array}{l}\text { hyp.syll. through that-which-connects / } \\
\text { removing from consequence }\end{array}$ \\
\hline- & $?$ & third indemonstrable & (See Section 3) \\
\hline- & in acc. w. division & fourth indemonstrable & $\begin{array}{l}\text { hyp.syll. through that-which-divides / } \\
\text { establishing from conflict }\end{array}$ \\
\hline- & in acc. w. division & fifth indemonstrable & $\begin{array}{l}\text { hyp.syll. through that-which-divides / } \\
\text { removing from conflict }\end{array}$ \\
\hline that-which-is-taken-instead & that-which-is-taken-instead & co-assumption & changed premise \\
\hline- & that taken in addition & co-assumption & that taken in addition \\
\hline & proving premise & (co-assumption) & categorical premise \\
\hline (hypothesis) & hypothetical premise & mode-forming assumption & hypothetical premise \\
\hline
\end{tabular}

Figure 2 shows that Alexander has succeeded in building up a vocabulary for hypothetical syllogistic that is in its entirety non-Stoic and based on Aristotelian and early Peripatetic terms.

\section{The problem of the negative conjunctions and the third indemonstrables}

Historically perhaps the most fascinating aspect of Alexander's appropriation of the Stoic indemonstrables for Peripatetic purposes is his treatment of the third indemonstrables and their mode-forming premises, the conjunction-negating assertibles. We know from Galen that there was a debate about the usefulness and validity of the Stoic third indemonstrables, and also that they had no early Peripatetic correlate. ${ }^{65}$ Galen himself rejected negative conjunctions with a contingent relation between the

\footnotetext{
${ }^{64}$ Maroth's conjecture that the early Peripatetics used the word hypothetical (i்o $\left.\theta \varepsilon \tau 1 \kappa o ́ \varsigma\right)$ for propositions and syllogisms ([Maroth 1989] 33, 34) is based on the wrong assumption that Alcinous is the same person as Galen's teacher Albinus and seems unfounded. Cf. [Bobzien 2002a].

${ }^{65}$ Pace Barnes [1985]; cf. my [2002a], [2002b].
} 
conjuncts (e.g. 'Theo walks and Dio talks') as unsuitable for producing syllogisms. But he considered negative conjunctions with partially incompatible conjuncts (i.e. those which cannot be true together, e.g. 'Theo is in Athens and Theo is on the Isthmus') suitable for syllogistic. He took them to express a relation of incomplete conflict and

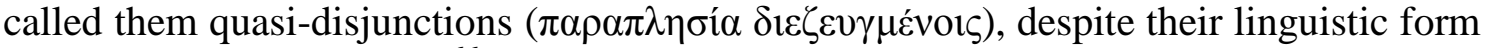
of a negative conjunction. ${ }^{66}$ Later Aristotle commentators reserved the 'third mode of the hypothetical syllogism', as they called it, for contraries with intermediates, and expressed their first premises grammatically as disjunctions. ${ }^{67}$

There are no signs that Alexander was acquainted with Galen's suggestions or with the alternatives chosen by the later commentators. Still, he was aware that there was a /221/ problem with the third type of indemonstrables and that there was a debate about it. We have no evidence that Alexander himself had a firm view on the matter. However, he is a valuable witness for the transitional period in which some Peripatetics, and presumably some Platonists, attempted both to retain all five Stoic types of indemonstrables, and to pass them all off as Peripatetic (or Platonist), as far as their origin, character, and justification are concerned. The four Early Peripatetic hypothetical syllogisms are thus augmented by a fifth. I consider the relevant passages in Alexander's commentaries in turn.

\subsection{The Prior Analytics commentary:}

In the above-discussed passage (3)(ii) Alexander lists three types of hypothetical arguments that Aristotle could have meant by "the other arguments that conclude from a hypothesis":

(3)(ii) He would mean the hypothetical <arguments> by means of that-whichconnects, which is also called a conditional, and the co-assumption, and the ones by means of that-which-divides, that is disjunction, and perhaps the ones by means of the negation of a conjunction. (Alex.An.Pr.390.3-6)

The first of these would encompass the first and second Stoic indemonstrables, the second the fourth and fifth Stoic indemonstrables, and the third the third Stoic indemonstrables. Two things are noteworthy in (3)(ii): First, for the conditional and disjunction, Alexander first uses his Peripatetic term and then glosses it by the Stoic one; but he presents only one expression (the Stoic 'negation of conjunction') for the third case. This suggests that either there was no terminological Peripatetic counterpart available to Alexander, or, if there was, it was referred to with the same or a similar expression as the Stoic. ${ }^{68}$ Second, this case is added with the tentative 'and perhaps' (i) кai). Thus Alexander seems to have some reservations as to whether Aristotle would have had arguments with negative conjunctions in mind.

The long passage An.Pr.262.28-265.5, (discussed in part in Section 1.1), in which Alexander attempts to show that the Stoics indemonstrables are Aristotelian syllogisms

\footnotetext{
${ }^{66}$ Cf. Gal.Inst.Log.5.1.

${ }^{67}$ E.g. Philop.An.Pr.245.3-23; [Ammon].An.Pr.68.23-41; see also Bobzien [forthcoming].

68 I assume that the early Peripatetics didn't have an expression for a counterpart to the third indemonstrables, since they didn't have such a counterpart; and that the Peripatetics in the $1^{\text {st }}$ century BCE (e.g. mentioned by Galen Inst.Log.7.2) may have taken over Stoic terminology with Stoic theory.
} 
from a hypothesis, both confirms these points, and makes them clearer. At the beginning $1222 /$ of the passage Alexander lists in Stoic terminology the three mode-forming premises used for the five indemonstrables: "the mode-forming <premise/assertible> being either a conditional or a disjunction or a conjunction"69 (An.Pr.262.31). Then he shows that the syllogisms with conditional premise and those with disjunctive premise fit Aristotle's description of syllogisms from a hypothesis: the former correspond to the first and second indemonstrables, the latter to the fourth and fifth ones. (Here again, he

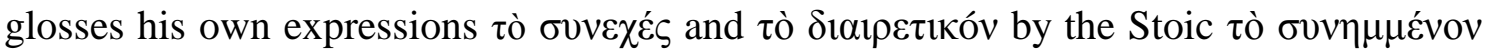
and $\tau$ ò $\delta \varepsilon \varepsilon \zeta \varepsilon v \gamma \mu \varepsilon ́ v o v$.) Third, he turns to the syllogisms from a negative conjunction. I quote the passage in full:

(11) But (15) also in the case of the <mode> from a negative conjunction <can it be shown that it belongs to Aristotle's syllogisms from a hypothesis $>$, if, that is, this mode differs from the previously discussed ones, and is not the same as that by means of a conditional which begins with an affirmation and ends in a negation, such as if $A$, then not $B{ }^{, 70}$ For in the case of these <syllogisms>, too, if the co-assumption requires proof, it is to be proved by means of a categorical syllogism. For example: 'it is not both the case that living pleasantly is the goal (20) and virtue is choiceworthy by itself. But virtue is choiceworthy by itself. Hence it is not the case that living pleasantly is the goal.' For that which has been co-assumed, i.e. 'virtue is choiceworthy by itself', is proved through a categorical syllogism. For example, ... (25) ... 'Hence virtue is choiceworthy in itself.' But if the same thing were assumed hypothetically in the following form: 'if pleasure is the goal, then it is not the case that virtue is choiceworthy in itself', then the consequence would be proved through a syllogism of this kind: ... . (Alex.An.Pr.264.14-31)

Alexander here considers two possibilities for the syllogism from a negative conjunction: either (i) it is different from the conditional and disjunctive hypothetical syllogisms or (ii) it is the same as one of the conditional modes. Alexander does not commit himself to either possibility. Instead, he demonstrates that either way the syllogism /223/ could be seen as a case of an Aristotelian syllogism from a hypothesis showing which is after all the purpose of An.Pr.262-4. It is likely that both options (i) and (ii) were discussed at Alexander's time. (i) implies the introduction of a Peripatetic correlate to the third indemonstrables without the claim of Peripatetic ancestry; (ii) enables the Peripatetics to argue that the hypothetical syllogism with a negative conjunction is one of those syllogisms the Peripatetics already accepted (namely a type of conditional hypothetical syllogism); it is just worded differently (and wording matters to the Stoics, but not the Peripatetics). ${ }^{71}$ Since Alexander does not commit himself to either view, and is rather tentative in his statements about them, ${ }^{72}$ it seems that at the

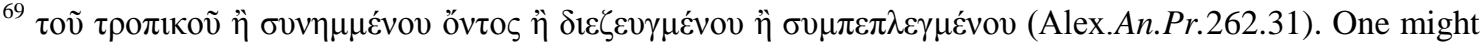
expect 'negative conjunction' rather than 'conjunction' here. However, since for Alexander the negative conjunction is a type of conjunction (whereas the Stoics have 'negation of a conjunction', classified as negation), from Alexander's perspective, what he says is correct, if unspecific.

${ }^{70}$ Or: 'if the first, then not the second' - the description of the conditional is entirely in Stoic terms, hence so might have been the illustration.

${ }^{71}$ A third possibility, one actually taken by later commentators, would be to add it and equate it with something else from Aristotle's logic, such as the case of contraries with intermediates.

${ }^{72}$ Cf. the 'ifs' at Alex.An.Pr.264.15 and 264.26.
} 
time there was no Peripatetic standard solution to the problem available. This notwithstanding, passage (11) sports some interesting features:

We consider option (ii) first: the indemonstrable mode from a negative conjunction (or negation of a conjunction, as the Stoics would say) is the same as a mode by means of a conditional. Alexander's description of the mode as "that by means of a conditional which begins with an affirmation and ends in a negation" suggests that he assumes that there are several different modes of the hypothetical syllogisms with a conditional hypothetical premise. Alexander here uses the Greek word 'mode' ( $\tau \rho$ ó $\pi$ o $)$ not in the Stoic, but in an Aristotelian or Peripatetic sense: one syllogistic figure has several modes. The conditional and disjunctive hypothetical syllogisms would be (the equivalent to) figures, in parallel to Aristotle's categorical syllogistic. Alexander's specification "such as "if A, then not B"" suggests that option (ii) might assume there to be eight different modes in the 'conditional figure': four of type modus ponens, four of type modus tollens, obtained by drawing out all possible combinations with affirmative and negative antecedent and consequent propositions. At Alexander's time, there was a similar Peripatetic use of 'mode' and 'figure' for wholly hypothetical syllogisms. ${ }^{73}$ Moreover, we know of such a classification of modus ponens and modus tollens arguments from Boethius and from the Anonymous Scholium Waitz. ${ }^{74}$ These two later texts don't discuss hypothetical syllogisms with a negative conjunction as hypothetical premise. So conceivably there was a faction of Peripatetic logicians that integrated the third Stoic indemonstrable into Peripatetic hypothetical syllogistic by equating it to the mode of the form $/ 224 /$ 'if A, not B; A; therefore not B' ${ }^{75}$ Note that the classification of 'if A, then not B' as mode of a conditional hypothetical syllogism differs from that of the early Peripatetics, who would have considered 'if A, then not B' as a - nonstandardly expressed - dividing (or disjunctive) proposition. ${ }^{76}$

What about option (i)? Who was the faction of Peripatetics (or other philosophers) that believed that the hypothetical syllogisms with a negative conjunction differ from the ones with a conditional or with a disjunction that Alexander discussed beforehand? They would be either the $1^{\text {st }}$ century BCE Peripatetics who adopted the Stoic indemonstrables; or alternatively, philosophers like Galen, who classified the negative conjunctive hypothetical propositions as among those that indicate a kind of conflict ( $\mu$ á $\chi \eta$ ), and thus among the other group of hypothetical syllogisms which the early Peripatetics distinguished. In the latter case, these hypothetical syllogisms, while being an independent kind, could still be subsumed under the early Peripatetic categorization

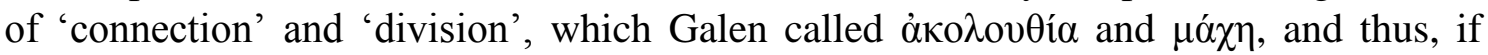
desired, could be reclaimed as Peripatetic in origin.

\subsection{The Topics commentary:}

One of the Topics passages discussed above in Section 1.2 shows in a different way that Alexander had not yet found a place for the third indemonstrables:

\footnotetext{
${ }^{73}$ See my [2000].

${ }^{74}$ See my [2002c].

${ }^{75}$ Later Aristotle commentators generally use the expression 'mode' ( $\tau \rho$ ó $\pi$ o $\varsigma$ ) differently: i.e. to denote the (by then) five different forms of hypothetical syllogisms: e.g. Philop.An.Pr.244.1-246.14, Anon.Log.etQuadr.38, Heiberg. (On Log.etQuadr.38 cf. Barnes [2002].)

${ }^{76}$ See my [2002a], [2002b].
} 
(10) And the proof that is fitting for the contraries without intermediates is rather the one by means of the so-called fifth indemonstrable, which is the one that concludes from that-which-divides and the contradictory to one of the <components> in that-which-divides the remaining <component>. But for the contraries with intermediates the <proof> by means of the fourth <indemonstrable is fitting $>$, which is the one that refutes from that-which-divides and one of the <components> in that-which-divides the other <component>.

We saw in Section 1.2 that Alexander uses the pattern of the fourth and fifth indemonstrables to describe how, by using them, one can obtain proofs. We noted that we would have expected him saying that the contradictories without intermediates fit the pattern of the fifth and the fourth indemonstrables. /225/

Now we have a closer look at Alexander's suggestion that the contraries with intermediates are such that the pattern of the fourth indemonstrables is fitting for them. The connection appears to be roughly this: when two terms are contraries with intermediates, then they are in conflict ( $\mu \alpha \dot{\chi} \chi \eta)$, since they cannot both hold of the same thing. The hypothetical premises or propositions that express conflict are the dividing (or disjunctive) ones. The inference patterns built on dividing (or disjunctive) hypothetical premises/propositions are those of the fourth and fifth indemonstrables. The pattern of the fifth indemonstrables does not 'fit' the contraries with intermedicates, since one cannot, for example, infer from the conflict of black and white that if this is not white, than it is black. It could be grey or yellow. But the pattern of the fourth indemonstrable does 'fit': we can safely infer from the conflict of black and white that if this is white it is not black. So far, so good.

We are left with two problems: Alexander's omission of the fact that the pattern of the fourth indemonstrables also fits the contraries with intermediates (and contradictories, of course). And the difficulty that the hypothetical propositions in the fourth and fifth indemonstrables are expressed in disjunctions, whereas disjunctions are not a suitable way for expressing the conflict of contraries with intermediates. We just don't say "this is either black or white" when we wish to express that particular kind of conflict.

The third indemonstrable is not at all considered by Alexander in the passages quoted from his Topics commentary (nor anywhere in the commentary), although it would lend itself perfectly to arguments using contraries with intermediates. Some later Peripatetics or Platonists solved both of Alexander's problems, by assigning both the pattern of the fourth and the fifth indemonstrables to the contraries without intermediates, and by assigning the pattern of the third indemonstrable to contraries with intermediates. ${ }^{77}$ The negative conjunction with component sentences that share the same subject term is the perfect grammatical vehicle for expressing contraries with intermediates. ('This is not both black and white. But it is black. Hence it is not white.') Alexander equipped these later philosophers with the connection of Aristotle's classification of opposites (from the Categories) with (i) the passages from Aristotle's Topics and with (ii) the Stoic indemonstrables. He thus laid the foundation for this later, more coherent, theory.

\footnotetext{
${ }^{77}$ See my [forthcoming].
} 


\section{Conclusion}

Alexander is the first known ancient author who both suggested that Aristotle was aware of the inference patterns the Stoics encapsulated in their theory of indemonstrables, and /226/ attempted to provide evidence for this fact by drawing a connection between the indemonstrables and selected passages from Aristotle's Organon. Furthermore presumably in order to support his view that Aristotle had considered such inference patterns, and to establish a Peripatetic theory of them (a hypothetical syllogistic) Alexander introduced a logical vocabulary that is based on Aristotelian and early Peripatetic terminology. He modified Aristotelian and early Peripatetic terms and their use in such a way that they fit a theory of syllogisms derived from the Stoic indemonstrables. The resulting elements of a hypothetical syllogistic are Peripatetic both in spirit and in nomenclature. Alexander did not manage to integrate the third Stoic indemonstrables into the Peripatetic system. But he provided the foundations for what later became the standard way of doing so.

The importance of Alexander in the development of a Peripatetic (and Platonist) propositional logic is thus twofold: first he does no longer condone the eclectic method used by earlier Peripatetics, who unabashedly (and sometimes without acknowledgement) took over parts of Stoic logic to complement Aristotelian logic. Instead, now, elements of Stoic logic that are integrated in Peripatetic theory have to be shown to have their origin in some Aristotelian (or early Peripatetic) thought. Second, Alexander paved the way for a full Peripatetic/Platonist hypothetical syllogistic by drawing a number of important, if sometimes somewhat far-fetched, connections between Stoic logic and Aristotle's Organon; connections on which later Aristotle commentators were able to build.

\section{Acknowledgements}

I am indebted to Fabio Acerbi and István Bodnár for helpful comments on a draft of this paper.

\section{References}

Barnes, J. (1984). 'Terms and Sentences: Theophrastus on Hypothetical syllogisms", Proceedings of the British Academy 69: 279-326.

Barnes, J. (1985). 'Theophrastus and Hypothetical Syllogistic', in J.Wiesner (ed.), Aristoteles Werk und Wirkung, vol.1 (Berlin/New York: De Gruyter) 557-576.

Barnes, J. (2002). 'Syllogistic in the Anon Heiberg', in K.Ierodiakonou (ed.), Byzantine Philosophy and Its Ancient Sources (Oxford: OUP).

Bobzien, S. (1996). 'Stoic Syllogistic', Oxford Studies in Ancient Philosophy 14: 133-92.

Bobzien, S. (1997). 'Stoic Hypotheses and Hypothetical Argument', Phronesis 42: 299-312.

Bobzien, S. (1999). 'Stoic Logic', in K. Algra et al. (eds), The Cambridge History of Hellenistic Philosophy (Cambridge: CUP) 92-157.

Bobzien, S. (2000). 'Wholly hypothetical Syllogisms', Phronesis 45: 87-137.

Bobzien, S. (2002a). 'The Development of Modus Ponens in Antiquity', Phronesis 47: 359394. 
Bobzien, S. (2002b). 'Pre-Stoic hypothetical syllogistic in Galen' in V.Nutton (ed.) The Unknown Galen, Bulletin of the Institute of Classical Studies, S77: 57-72.

Bobzien, S. (2002c). 'A Greek Parallel to Boethius' De Hypotheticis Syllogismis', Mnemosyne 55: 285-300.

Bobzien, S. (2004). 'Hypothetical Syllogistic in Galen - Propositional logic off the rails?' Rhizai: Journal for Ancient Philosophy and Science 2: 57-102.

Bobzien, S. (forthcoming). 'The making of a Platonist Hypothetical Syllogistic'.

Frede, M. (1974). Die stoische Logik (Göttingen: Vandenhoeck\&Ruprecht).

Frede, M. (1975). 'Stoic vs. Peripatetic Syllogistic', Archiv für Geschichte der Philosophie 56: 99-124.

Goulet, R. (1978). 'La classification des propositions simples', in J.Brunschwig (ed.), Les Stoïciens et leur Logique (Paris: Vrin) 191-222.

Ierodiakonou, K. (1990). 'Rediscovering some Stoic arguments', in P.Nicolacopoulos (ed.), Greek Studies in the Philosophy and History of Science (Dordrecht: Kluwer) 137-148.

Maroth, M. (1979). 'Die hypothetischen Syllogismen', Acta Antiqua 27: 407-36.

Maroth, M. (1989). Ibn Sina und die peripatetische "Aussagenlogik" (Leiden: Brill).

Mignucci, M. (1993). 'The Stoic Themata', in K.Doering and Th.Ebert (eds) Dialektiker und Stoiker (Stuttgart: Franz Steiner) 217-238.

Mueller, Ian (1969). 'Stoic and Peripatetic Logic', Archiv für Geschichte der Philosophie 51: 173-187.

Mueller, I. (2006). Alexander of Aphrodisiac: on Aristotle's Prior Analytics 1.23-31 (London: Duckworth).

Schiefsky, M. (This volume).

Speca, A. (2001). Hypothetical Syllogistic and Stoic Logic (Leiden: Brill).

Street, T. (2001). 'The "Eminent Later Scholar" in Avicenna's Book of the Syllogism', Arabic Sciences and Philosophy 11: 205-218.

Striker, G. (1979). 'Aristoteles über Syllogismen "aufgrund einer Hypothese"', Hermes 107: $33-50$.

Striker, G. (2009). Aristotle, Prior Analytics: Book I (Oxford: OUP). 